\title{
Retórica y organización del discurso en El ritual de los Bacabes
}

\section{Rhetorics and Patterns of Discourse in the Ritual of the Bacabs}

\author{
Michela Craveri \\ Universidad Católica de Milán, Italia
}

\begin{abstract}
Resumen: En este trabajo propongo el estudio de la organización retórica de $\mathrm{El} \mathrm{ri-}$ tual de los Bacabes, documento colonial de primera importancia en el contexto de la literatura maya yucateca. Después de un análisis filológico del manuscrito me enfocaré en el estudio de la retórica textual y de las marcas de oralidad presentes en el documento. También me dedicaré al estudio del simbolismo textual y de las redes paronomásticas, capaces de vincular en el mismo acto curativo enfermedades, partes del cuerpo, animales y plantas medicinales. El análisis de su organización retórica y de los mecanismos textuales de producción de sentido nos permite comprender las funciones del lenguaje ritual y la presencia de un sistema codificado de recursos retóricos y de producción de sentido. El enfoque teórico escogido parte de la convergencia entre la retórica y los estudios semióticos del discurso.
\end{abstract}

Palabras clave: El ritual de los Bacabes; literatura maya; retórica indígena; medicina maya; estilo ritual maya.

Aвstract: The aim of this paper is to study the rhetorical structure of the Ritual of the Bacabs, a colonial document of great importance in the context of Yucatec Maya literature. After a philological analysis, I will focus especially on the study of textual rhetoric and the marks of orality of this ritual document. I will also study the textual symbolism and networks of paronomasias, used to link diseases, body parts, animals and medicinal plants in the same healing action. The analysis of its rhetorical organization and the textual mechanisms of meaning production allows us to understand the functions of ritual language and the presence of a codified system of discourse. The basis of my theoretical approach is the convergence between rhetoric and semiotic study of discourse.

KeYwords: Ritual of the Bacabs; Maya literature; indigenous rhetorics; Maya medicine; Maya ritual style. 
ReCEPCIÓn: 20 de enero de 2020.

ACEPTACIÓN: $1^{\circ}$ de mayo de 2020.

Dol: https://doi.org/10.19130/iifl.ecm.57.2021.18657

\section{Premisas metodológicas}

El documento llamado El ritual de los Bacabes recoge un patrimonio de especial valor cultural (Ritual of the Bacabs, s.f.). El manuscrito alfabético contiene textos medicinales transcritos en maya yucateco durante la época colonial, posiblemente a partir de una tradición oral (Roys, 1965: X). A pesar de la presencia de una tradición médica de antigua prosapia en el área maya, son muy escasos los documentos que recogen testimonios de primera mano del discurso médico indígena colonial. La escasez de estos textos se debe, por un lado, al carácter clandestino de tales prácticas culturales en la época colonial, y por otro, a la eficacia de la tradición oral, que ha permitido la conservación hasta hoy del saber médico maya fuera de los circuitos de las instituciones occidentales (Rodríguez, 2012: 65).

La finalidad de este trabajo es la de estudiar la organización retórica de $E l$ ritual de los Bacabes y evidenciar la presencia de recursos estilísticos específicos de este género textual. Mi perspectiva metodológica se basa en la convergencia entre la retórica y la semiótica, disciplinas que a mi parecer pueden dar razón del proceso de creación textual y de producción de sentido. El diálogo entre ambas disciplinas es especialmente fértil, ya que un análisis retórico puede esclarecer un tema central en los estudios semióticos, o sea el problema de la construcción del discurso y por ende de la elaboración del sentido (Solís, 2009: 114).

La cooperación entre retórica y semiótica tiene varias finalidades, todas fundamentales en el estudio de la significación textual. En primer lugar, puede explicar las operaciones que intervienen en la constitución de figuras; en segundo término, puede llevar a cabo una clasificación del acervo figurativo del género textual y de la cultura, y por último reconocer a la cultura misma el papel de constructora y decodificadora de tal acervo figurativo (Solís, 2009: 114). Un estudio retórico, en su correlación con el enfoque semiótico, tiene como objetivo identificar los mecanismos y las figuras activas en un sistema textual y al mismo tiempo enfocarse en los resultados de estos mismos en el plano de las significaciones. Mi enfoque hermenéutico en el estudio del lenguaje de El ritual de los Bacabes parte entonces de estas premisas, de la convergencia entre estas dos disciplinas.

Según la propuesta semiótica de la escuela de Lotman, se pueden reconocer en las culturas distintos textos y productos culturales focalizados hacia el hablante o el oyente. En el caso de comunicaciones focalizadas hacia el oyente, se trata de textos transparentes, poco codificados, con una fuerte función referencial. Dichos textos tienden a ser accesibles al oyente y de esta forma tendrán un grado mínimo de construcción. Por otro lado, los textos orientados hacia el hablante tendrán una codificación máxima, como en el caso de textos esotéricos y crípti- 
cos o del lenguaje sacerdotal, enfocados en quien los pronuncia, en su estatus y su carácter de iniciado (Vjaceslav et al., 2006: 120-123). A mi parecer entran en esta segunda categoría los textos medicinales de El ritual de los Bacabes, que los terapeutas mayas coloniales pronunciaban para luchar contra las enfermedades y sanar el cuerpo y el alma del paciente. Se trata de un lenguaje polisémico, retóricamente marcado, que responde a las funciones del texto poético, o sea las funciones connotativa, fática y estética propuestas por Jakobson (Jakobson, 1963; Guiraud, 1996: 13-15). También los otros elementos participantes, el destinatario y el referente, son esenciales en la comunicación médica; sin embargo, el punto fundamental es la capacidad del terapeuta de crear una espesa red de significación que connote simbólicamente al referente y al destinatario, según estrategias retóricas específicas.

En este artículo no me centraré en el estudio de los tratamientos médicos y del concepto de salud y enfermedad para los mayas coloniales; para ello remito a excelentes trabajos específicos sobre el tema, como los de Roys (1976), Chávez Guzmán (2013) e Hirose (2008). Mi análisis se centra en el lenguaje y en los mecanismos retóricos de funcionamiento del discurso médico de El ritual de los Bacabes. En cuanto texto polisémico, parto del estudio de su retórica y de la consideración del texto como espacio semiótico de múltiples capas. A pesar de la clasificación generalizada de los documentos médicos como parte de un género textual utilitario, con una finalidad curativa, fuera del canon literario occidental, en mi opinión estos textos corresponden al sistema semiótico de la poiesis, "poesía", en su sentido etimológico de "creación, acción, construcción" de sentido, en razón de su función connotativa (Corominas, 1987: 465; Corripio, 1984: 369; Guiraud, 1996: 40-41).

Sólo un estudio que respete las múltiples capas semióticas del discurso puede dar razón de su significado cultural. Esto quiere decir proponer un análisis que no se base en una separación en géneros textuales de tipo occidental, sino al contrario, que parta precisamente desde los mecanismos de creación de polisemia, para comprender la función trasversal de su retórica. Ésta por un lado tiene como fin marcar el carácter críptico del lenguaje médico, y por otro favorecer la memorización del texto; por último, sugerir la red de múltiples significados de los referentes comunicados. Es el juego combinatorio de las leyes y el modo en que se organizan en el texto, lo que comunica y produce las capas de significaciones (Ferrari, 1975: XII-XIII).

\section{El manuscrito de El ritual de los Bacabes}

El manuscrito alfabético de El ritual de los Bacabes fue descubierto en Yucatán entre 1914 y 1915 por Frederic Smith. William Gates lo adquirió en 1930 y fue quien le dio el nombre con el que se le conoce actualmente, por las repetidas invocaciones a las deidades de los rumbos cósmicos (Roys, 1965: VII). El docu- 
mento pasó a las manos de Robert Garrett, que en 1949 lo donó a la biblioteca de la Universidad de Princeton, donde se encuentra actualmente. ${ }^{1}$

El manuscrito se presenta bajo la forma de libro y contiene 76 textos, de los cuales 49 son rezos ceremoniales contra las enfermedades y los 27 restantes, recetas médicas. Cada plegaria tiene una estructura repetida, ya que se abre con un título y se cierra con el préstamo cristiano amen (sic). Los cantos tienen una estructura textual cerrada y a menudo concluyen con líneas continuas que marcan el cierre de un texto y el principio del siguiente. Es evidente en ello una traducción cultural, desde el material heterogéneo oral hasta la sistematización gráfica y semántica de los cantos en las páginas del libro de matriz europea. Sin embargo, desde una perspectiva semiótica, la demarcación o las fronteras entre un texto y otro no representan líneas de separación, sino espacios de interconexión (Sedda, 2006: 42-43), tanto que podemos considerar El ritual de los Bacabes como una expresión cultural estratificada pero homogénea, con redes conceptuales entre un canto y otro y modelos discursivos de constante profundización.

\section{Fechas y conformación del manuscrito}

El libro consta de 164 folios en papel europeo de $15.3 \times 10 \mathrm{~cm}$. Posiblemente se ha perdido la página inicial, puesto que el primer folio escrito empieza a la mitad de una frase y no lleva el título de la plegaria, a diferencia de lo que ocurre en los otros casos. Aparecen varias páginas en blanco, no numeradas, al principio y al final del documento, pero sobre todo en el reverso de dos páginas escritas, conformando un esquema muchas veces repetido - pero no constante- de dos páginas escritas y dos en blanco, y así continúa en las siguientes.

El documento presenta dos numeraciones en la parte superior de los folios, una más antigua de influencia maya, con varios errores y saltos de página, y otra mucho más reciente. Los dos sistemas corren paralelos. Por un lado, se aprecia la numeración arábiga progresiva más reciente, anotada en la esquina superior de cada página escrita, de 1 a 237 . Tales anotaciones numéricas parecen haber sido añadidas posteriormente, con una grafía moderna, una punta más fina y tinta negra. Otra numeración, también arábiga, corre desde la página 4 hasta la 176, para aparecer con una última anotación en la 236. Esta segunda numeración de las páginas es muy interesante; posiblemente es anterior a la otra y revela la subsistencia de un sistema numérico mixto, decimal y vigesimal. Se evidencian algunos errores que nos ayudan a comprender el sincretismo cultural del copista, por ejemplo cuando en lugar de 10 el copista escribe 0 y en lugar de 20 escribe $02 \mathrm{o}$ el 101 escrito 01 . El análisis de esta anotación numérica parece revelar la persistencia de un sistema vigesimal, aun latente, ya que los errores en la inversión de

\footnotetext{
${ }^{1}$ Ritual of the Bacabs. Manuscrito C0744.01, Garrett-Gates Mesoamerican Manuscripts, núm. 1, Princeton University.
} 
las cifras se repiten sobre todo en el caso de veintenas y múltiplos de veintenas, y también cuando en lugar de 119 escribe 009, en alusión al cumplimiento de una posición numérica. Además, la repetición de algunos numerales en lugar del número consecutivo nos sugiere que el copista no dominaba completamente el sistema numérico hispánico y esto nos ayuda a comprender la persistencia en la época colonial del antiguo cómputo vigesimal.

Los últimos dos folios están escritos en el reverso de una bula impresa en español y fechada en febrero de 1779. Curiosamente los copistas tuvieron la idea de usar una bula destinada a extirpar la idolatría para registrar sus rituales autóctonos, tal vez con la finalidad de esconder su contenido clandestino o simplemente para aprovechar un pedazo de papel.

El último folio lleva escrito a mano el nombre de Joan Canul, posiblemente el cacique de Nunkiní en la segunda mitad del siglo xvi. Dicho nombre aparece al final del documento como escribano, según prescribían las leyes españolas en relación con los documentos oficiales del cabildo. Es evidente que en este caso el cacique de Nunkiní mantuvo el poder político y cultural, al ser el depositario de las dos tradiciones escriturales, la europea y la autóctona (Chuchiak, 2010: 97). No se puede descartar que su identidad no coincida con el mencionado cacique, ya que el apellido Canul se refiere a un linaje noble, al cual seguramente pertenecían varios escribanos de las provincias de Calkiní y Maxcanú (Chuchiak, 2010: 101; Chávez, 2013: 21). En el último folio aparece otra firma, pero desgraciadamente es ilegible y no da indicaciones posibles para fechar la última transcripción.

Con mucha probabilidad, la finalidad de la transcripción alfabética era la de conservar el saber ancestral, pero sobre todo la de afirmar el reconocimiento de la autoridad y liderazgo del cacique y de su linaje, como en otros documentos rituales mayas coloniales, entre los cuales figuran los Chilames (Chilam Balam de Ixil, 2011; Chilam Balam de Kahua, s.f.; Libro de Chilam Balam de Chumayel, 1988; Chávez, 2013: 32).

El documento que conocemos hoy parece ser la copia de un manuscrito del siglo xvi trascrito en Nunkiní, probablemente la versión alfabética de un códice prehispánico. Las referencias a la escritura son numerosas en el texto, cuando se afirma repetidas veces: $c i$ bin yalabal uooh / ci bin u nuc than, "pues se dice que es la palabra de los glifos, pues se dice que es su respuesta" ${ }^{2}$ (pp. 35, 52, 55, 58) ${ }^{3}$ o yanhi bin u uohil xan, "se dice que es su glifo también" (p. 41). La palabra clave aquí es uoh, "carácter o letra", según el Calepino de Motul (1995: 764), posiblemen-

\footnotetext{
2 Se respetan aquí la ortografía y las elecciones gráficas de la fuente colonial. La paleografía de todos los pasos citados de El ritual de los Bacabes es de Bolles (2003); la traducción de éste y de los siguientes pasos del maya al español es mía. También es mía la organización gráfica de la versificación.

${ }^{3}$ A lo largo del este artículo, para no sobrecargar las citas, al referirme a El ritual de los Bacabes, emplearé entre paréntesis las páginas del manuscrito al que hago referencia, publicado en su versión paleográfica por Bolles (2003) y disponible en versión facsimilar. Todas las demás citas bibliográficas mantienen el sistema solicitado por las normas editoriales de la revista.
} 
te en referencia a textos jeroglíficos que ilustraban el uso de hierbas y remedios medicinales (Chávez, 2013: 242). Muy probablemente, la escritura maya convivió con la alfabética entre los miembros de la élite letrada indígena por lo menos hasta 1750. Podemos suponer que los escribanos mayas sabían manejar ambos sistemas gráficos y pasar de uno a otro según las funciones y los destinatarios de los documentos (Chuchiak, 2010: 90-92; Chávez, 2013: 242).

En la página 191 se nota la interpolación de unas palabras en el margen (tin ma), así como entre las líneas de la página 208 (ekel hucke), muy probablemente un error de trascripción de un texto a otro. También hay abreviaciones como en ' $y$ y $y$ ' por 'yetel yetel yetel', que nos indican que hay que seguir con la secuencia en las páginas $6,12,84$, entre otras. También cabe mencionar algunos errores de transcripción, como la repetición de una parte de los textos 6 y 8 o la repetición idéntica de una receta médica (p. 226) o la presencia de un texto incompleto (p. 229). Estos elementos parecen indicar que el copista estaba realizando una trascripción a partir de otro texto.

\section{Los copistas y su universo cultural: análisis filológico}

Los textos contenidos en El ritual de los Bacabes parecen ser obra de dos copistas, aunque no conocemos sus nombres, ni el de los sacerdotes y terapeutas que dictaron estos textos (Roys, 1965: VII; Bolles, 2003: III). Además de un copista principal, ocasionalmente aparece otra mano responsable de la interpolación de textos en las páginas dejadas en blanco por el primer copista, como ocurre con otros documentos coloniales (Gubler, 2014: 24). Entre los textos interpolados figuran "El gran cuerpo de la serpiente", posiblemente con referencias fálicas, en las páginas 20-21; el texto "Para la curación del viento del delirio de Nicte", en las páginas 61-62, y la "Plegaria de los huesos", en las páginas 221- 237 (Bolles, 2003: III). La diferencia principal de las dos manos reside en diferentes estilos caligráficos, muy evidentes en la escritura de algunas letras.

El manuscrito que se conserva hasta hoy parece haber sido redactado entre 1779 , fecha de la bula, y 1813 . Ya no se emplea la cedilla, suprimida en 1740 por Pedro Beltrán de Santa Rosa (Barrera, 1980: 351). Por otro lado, el uso del signo $\checkmark$ para indicar el sonido $d z$ sugiere una fecha de redacción anterior a 1813, año de la introducción de la imprenta en Yucatán. A partir de ese momento, se empezó a usar la $d z$ por la $\jmath$, ya que no existía el carácter tipográfico correspondiente. Sin embargo, ello no impidió que en las áreas rurales se siguiera usando este signo aun después de tal fecha. ${ }^{4}$ El uso de ciertos signos gráficos no siempre es consistente, ya que el copista principal a veces registra las letras $\mathrm{h} o \mathrm{p}$ heridas, y a veces no (Bolles, 2003: III). El uso de la mayúscula y de la puntuación es muy

\footnotetext{
${ }^{4}$ Ana Patricia Martínez Huchim, comunicación personal, mayo de 2013.
} 
irregular y no responde aparentemente a razones semánticas o gramaticales (Bolles, 2003: IV), tal vez se refiere a las cláusulas del códice de referencia.

A partir del análisis de la numeración y de las manos que intervienen en los textos podemos deducir que El ritual de los Bacabes es el resultado de un procedimiento de traducción cultural complejo y estratificado, desde un posible códice prehispánico y la tradición oral, hasta una versión alfabética o mixta del siglo xvl, para llegar a distintas fases de trascripción e integración entre finales del siglo xVIII y principios del xix. Sabemos con seguridad que varios caciques manejaban ambos sistemas de escritura, también en plena época colonial (Chávez, 2013: 242).

Con mucha probabilidad el manuscrito fue encuadernado en una época posterior a su redacción alfabética, con unos folios en blanco, de los cuales algunos fueron aprovechados por el segundo copista para la interpolación de nuevos textos. Una primera versión comprendía las 73 páginas numeradas en gris, luego integradas con los otros textos de la segunda mano y sucesivamente numerados en su integridad por la segunda numeración en negro.

La segunda mano es de una fecha más tardía; fue escrita en las hojas dejadas en blanco por la primera mano, sin la numeración más antigua, sólo aplicada a las hojas escritas anteriormente; es la que comprende el mayor número de hispanismos y sincretismos religiosos en pocas páginas (“Jesus maria”, pp. 20, 63, 237; "Rosario", p. 20; "Dios yumbal y Dios mehenbil y Dios espiritu santo Amen", p. 221; "sortijas", p. 20; “aceite”, p. 70; “león”, p. 236). Se observa un buen uso de las palabras en español, a diferencia de los préstamos en otros documentos más tempranos que presentan evidentes adaptaciones graficas al sistema fonológico maya. La transcripción correcta de los préstamos parece ser una característica de los documentos redactados en la región occidental de la península yucateca, por el mayor contacto cultural con los evangelizadores y alfabetizadores (Chuchiak, 2010: 99-100, 103).

En general los hispanismos son muy escasos en El ritual, sobre todo en la parte recopilada por la primera mano, con pocas excepciones: en su misma versión gráfica, podemos mencionar "Remendio" (p. 214), "Jesuz maria" (p. 205), "Dios yumbil" (p. 15), "Dios yumbil y Dios mehenbil y Dios Espiritu Santo Amen” (p. 211) y la palabra "amen", que cierra casi todos los textos y que sugiere la presencia de un marco discursivo modelado según el patrón cristiano (Chávez, 2013: 22). La escasa presencia de un vocabulario sagrado referido a Dios es muy significativa, ya que la orden franciscana en particular manifestó el afán de hispanizar el vocabulario sagrado indígena para escindir los nombres mayas de su contenido "pagano y subversivo". Su base filosófica nominalista llevó a la negación de los universales y a la búsqueda de términos precisos para designar los referentes americanos (García-Ruiz, 1992: 88-92).

La lengua maya utilizada no presenta huellas de un contacto linguístico profundo con el español, ni a nivel gramatical ni léxico. Se evidencian algunos calcos semánticos al definir a una deidad yum, "padre, señor" (pp. 46, 62, 101) y "dios 
yumbi y dios mehenbil y dios espiritu santo", "Dios padre, Dios hijo y Dios espíritu santo" (p. 211; Hanks, 2010: 351). También se señala otro posible calco en sacal Anon, sac uinic (pp. 128-130), en alusión a anon o anom, el primer hombre de la creación maya (Calepino de Motul, 1995: 59) y el adjetivo sacal, que además de significar el color blanco, en composición con ciertas palabras, disminuye la significación y puede indicar cierta imperfección (Calepino de Motul, 1995: 151). También es interesante mencionar otro hispanismo, en la referencia a un huevo de gallina como remedio médico, con el término cax, "gallina" (de caxtlan, CoRdemex, 1980: 153-155).

La tan escasa presencia de hispanismos en la lengua de este documento nos permite confirmar la fecha temprana de su primera composición, posiblemente en el siglo xvı. Ya a partir de finales de ese siglo empiezan a penetrar de manera más consistente en el maya peninsular términos religiosos cristianos, nombres de plantas, animales o productos europeos, sobre todo en relación con la vida cotidiana (Lockhart, 1998: 35-41). Con la excepción del huevo de gallina, es singular también la ausencia de otros ingredientes y plantas medicinales de la farmacopea europea, que seguramente habían empezado a circular muy pronto en la Nueva España (Gubler, 2014: 19). Por otro lado, en varias secciones de los libros del Chilam Balam los redactores mayas mostraron mucho más interés en las prescripciones españolas, especialmente en lo referente a las enfermedades importadas por los conquistadores, ya que los mayas obviamente carecían de remedios autóctonos para estos padecimientos (Chilam Balam de Ixil, 2011; Chilam Balam de Kahua, s.f.; Karttunen, 1998: 432).

Más consistentes son los nahuatlismos, que desgraciadamente no nos dan indicaciones muy valiosas sobre la fecha del documento puesto que pueden haber pasado al maya ya desde la época prehispánica. El léxico de influencia náhuatl comprende: metnal (varias veces: pp. 9, 62, 108, 134-135, 203-205, 214), de mictlan, el Inframundo azteca (Siméon, 1996: 275); el nombre de una deidad Ix Malin Cacau (pp. 23-24), la Señora Malin Cacao, tal vez de malinalli, "cuerda, paja torcida”, también "día del calendario ritual” (Siméon, 1996: 251); maxcal (pp. 8, 64, 68), posiblemente de temazcalli, "baño de vapor” (Siméon, 1996: 469); xuchit (pp. 84 y 180-183), de xochitl, "flor" (Siméon, 1996: 774); anahte (p. 205), del náhuatl amatl, "papel, carta, etc." (Siméon, 1996: 23); y el sufijo reverencial -tzin (p. 24) (Siméon, 1996: 728).

\section{La organización del discurso y la "figurativización" del texto}

El estilo esotérico de El ritual de los Bacabes sigue el patrón del lenguaje de Zuyuá o Suyua, como está indicado directamente en uno de los textos: U lubul tan Suy ua in thanab nakukul, "es la caída del lenguaje de Suyua en mis palabras en la casa del quetzal” (p. 203). La palabra suyua es de difícil traducción, podría estar relacionada con la palabra sujuy, "virgen, puro" o con la palabra suuy (pool) "remolino 
de la cabeza". ${ }^{5}$ Lo que sí sabemos es que se refiere a un lenguaje figurado, muy importante en el sistema político y religioso maya.

El estilo ritual para iniciados tiene muchas evidencias en los textos mayas coloniales, como los libros del Chilam Balam de Chumayel (1988: 71-83) y de Tuzik (1981; Arzápalo, 2004: 84-87; Cocom, 2004: 79-81). En estos documentos, el manejo del lenguaje de Suyua se revela esencial para poder acceder al poder político (Nájera y Morales, 2009: 247-249; Morales, 2006: 60). En los ejemplos registrados en el Libro del Chilam Balam de Chumayel (1988: 71-83) resulta claro que el iniciado debe saber reconocer nexos metafóricos entre ciertas expresiones linguísticas y los referentes aludidos. El uso metafórico es tan sistemático que el nivel literal y el significado figurado no se pueden escindir. Ambos niveles conviven paralelamente en la significación textual.

El lenguaje de Suyua forma parte, según la perspectiva semiótica, del género discursivo orientado hacia el emisor, con una codificación máxima, ya que el uso de un estilo retórico específico por un lado marca el estatus especial del hablante, el sacerdote y el iniciado, y por otro, el valor sagrado de su referente y sus destinatarios, las enfermedades y las fuerzas divinas que las rigen (Vjaceslav et al., 2006: 120-123).

Las peculiaridades de este lenguaje codificado en El ritual de los Bacabes se reflejan en el uso especial de la lengua, con la elisión de algunas preposiciones y de algunos morfemas verbales de modo y aspecto. También es frecuente en el manuscrito la elisión de la glotalización de las vocales y la variación fonética de $t$ por $d z$ o $t z$ por $d z$, posiblemente por razones estilísticas (Arzápalo, 1987: 13-16; Arzápalo, 2004: 87-89). Muchos de los recursos poéticos presentes en El ritual de los Bacabes tienen una gran antiguiedad, como se puede observar en las inscripciones y en los códices prehispánicos, en donde abundan anáforas, paralelismos, difrasismos, metonimias y metáforas (Garza, 2008: 111).

\section{El carácter ritual del discurso terapéutico}

El lenguaje ritual es el lugar privilegiado de la actuación, es "una forma de hacer cosas" (Sidorova, 2000: 97). Por ello es tan importante el uso de una lengua especial, que no es la profana de la comunicación cotidiana sino el lenguaje codificado, apto para dialogar con los dioses y transformar la realidad (Martel, 2004). En virtud de su carácter especial, su retórica convierte la voz del terapeuta en una fuerza capaz de superar los umbrales de este mundo y penetrar en la significación profunda de las cosas. La fuerza tangible de su palabra se realiza tanto sobre los seres invisibles como sobre los visibles, llevando a cabo una verdadera negociación entre el plano humano y el divino (Sidorova, 2000: 97). Su fuerza consiste en una capacidad integradora. El lenguaje de Suyua por un lado actúa a

\footnotetext{
${ }^{5}$ Miguel Óscar Chan Dzul e Irma Pomol Cahum, comunicación personal, 30 de mayo de 2020.
} 
nivel fonológico, creando aliteraciones y anáforas, que sugieren una continuidad rítmica entre las ideas comunicadas, y por el otro funciona a nivel semántico, juntando lo que es diferente, ya que "pone en relación dos pensamientos y significa las cosas en acción” (Ricoeur, 1980: 52).

Para llevar a cabo su acto curativo, el terapeuta dialoga con las deidades para interceder por el paciente o ahuyentarlas desde su cuerpo. Penetra en el Metnal, regresa al origen del tiempo y colabora con los muertos, posiblemente en estados alterados de conciencia (Chávez, 2013: 123-124, 282). En virtud de su estatus y del manejo de una retórica específica, actúa sobre distintos niveles. En primer término, a través de una estructura narrativa cíclica desentraña la tupida red de significados físicos y espirituales de los padecimientos; en segundo lugar, identifica las posibles convergencias entre las enfermedades del paciente, las plantas, los animales y los ritmos cósmicos, como los ciclos del sol, de la luna y de las estrellas (Roys, 1965: CVIII).

Las enfermedades se asocian, por distintos principios simbólicos, con varios animales, entre los que figuran algunos mamíferos, serpientes y anfibios, pero sobre todo pájaros. Estos animales tienen un papel preponderante en la definición de las enfermedades, como mut, "pájaro" y también "presagio, buena o mala fama" (Calepino de Motul, 1995: 535) y ch'ch'il, "pájaro agüero, presagio" (Calepino de Motul, 1995: 263). En esta categoría están comprendidos también los insectos, tal vez considerados portadores de enfermedades desde el Metnal (Roys, 1965: XII-XIII).

Se detallarán a continuación las características principales de este lenguaje en El ritual de los Bacabes. Quisiera aclarar que el estudio retórico que presento aquí parte de un análisis de la transcripción alfabética de los textos, que por lo tanto no puede basarse en análisis prosódicos y fonéticos de tipo pragmático. Seguramente tenía gran importancia el sonido de tambores y otros instrumentos musicales, el canto, el baile, el ritmo de la voz y otros aspectos del acto comunicativo que se han perdido definitivamente en la versión escrita (Chávez, 2013: 224). Sin embargo, la organización del discurso, aun en la versión alfabética, nos puede dar pautas claras de los modelos retóricos y semióticos que el texto pone en marcha en la construcción de sentido.

\section{El patrón oral del lenguaje médico}

A pesar de la transcripción alfabética y de la muy probable presencia de un documento escrito de referencia, los textos rituales contenidos en el manuscrito del siglo XVIII-XIX presentan características estilísticas orales. Este modelo responde a dos razones: garantizar la memorización del texto por parte del hablante y reflejar una visión integradora de la realidad, donde cada frase representa un progresivo acercamiento al referente. Con el concepto de "oralidad" me refiero tanto a las técnicas de transmisión de textos orales, como al mismo acto enunciativo, que en el caso de los textos formalizados sigue pautas sintácticas y retóricas 
específicas. Las subordinadas son muy escasas y se reducen a algunas temporales y causales, necesarias para sugerir los nexos entre las ideas. El esquema predominante es la coordinación sintáctica, propia de la oralidad (Denny, 1991: 106-107). Esto nos indica que el manuscrito recoge una tradición más antigua, transmitida oralmente. Se trata de un modelo de progresiva profundización, a través de la expresión de distintos sujetos que intervienen en la acción y la distribución de los puntos de vista.

\author{
U lubtun bin tu can be \\ tu can lub \\ Ycnal ix ho[l]can be \\ Yicnal cit ho[l] can lub \\ Ten c lub a ch'u' tancase \\ $\mathrm{Ci}$ bin yalab tumenel ix [h]o[l] can be \\ Ix [h]o[l] can lub \\ Ci bin u kam than ah oc tancas bacin (p. 19). \\ Es su caída, dicen, en los cuatro caminos \\ en los cuatro descansaderos \\ junto a Ix Hol Can Be \\ junto a Cit Hol Can Lub \\ yo voy a tirar tu bromelia, delirio, \\ Pues así es dicho por Ix Hol Can Be \\ Ix Hol Can Lub \\ Pues así es dicha la respuesta de Ah Oc Tancas, tal vez.
}

Otro elemento propio de la oralidad es la recurrencia de deícticos, en particular de adjetivos demostrativos y adverbios de lugar (uaye, "aquí"; $t i$, te, "allí, allá", "hacia allá"), que tienen la función de vincular la acción ritual con el cuerpo del paciente y la situación espacio-temporal del acto curativo, evidentes en la repetición de fórmulas como:

Ti ta ch'ah a kinami

Ti ta ch'ah a uikali

[...]

Ti ta ch'ah a kinami

Ti ta ch'aah a uikali (p. 203).

Allí recobras tu fuerza

Allí recobras tu aliento

[...]

Allí tomas tu fuerza

Allí tomas tu aliento. 


\section{La estructura profunda del lenguaje médico: análisis semiótico de la organización del discurso}

El análisis de los textos parece indicar que cada uno de ellos está concebido como una unidad discursiva, con una estructura circular. Casi siempre acaban con el préstamo cristiano "amén", escrito en una línea separada a conclusión del texto. Si bien puede tratarse de una palabra maya, de significado críptico, escondido detrás del préstamo, más probablemente la adopción de un término cristiano tiene una precisa finalidad. Por un lado esconde el contendido clandestino del ritual, por otro expresa un sincretismo religioso en la réplica de la estructura de las plegarias cristianas. Fue muy frecuente en las prácticas religiosas mayas coloniales la incorporación de elementos cristianos, adaptados dentro de estructuras discursivas y conceptuales indígenas. En muchas ocasiones, dentro o en la conclusión de los cantos sagrados mesoamericanos de la época colonial se observa precisamente la integración del léxico religioso cristiano (Chávez, 2013: 54, 357).

En algunos casos el copista ha marcado también una o más líneas seguidas, para señalar gráficamente el paso de un canto al siguiente. Además, cada texto, a exclusión del primero, tiene como encabezado un título, que indica el tema y el tipo de enfermedad que se pretende curar. Es evidente que el encabezado y el cierre con el préstamo cristiano constituyen un marco narrativo de influencia europea, que poco encaja con la naturaleza oral y ritual de este lenguaje.

La separación gráfica entre los cantos no impide su interconexión. Al contrario, desde el punto de vista semiótico, es precisamente su línea de demarcación lo que hace vivir la significación textual, ya que proporciona a los textos su misma estructura y su patrón de repetición de formas y conceptos (Sedda, 2006: 4243). Las líneas de demarcación y el préstamo cristiano funcionan como líneas de conexión entre un texto y otro y entre distintos espacios semióticos: la oralidad fluida y la estructuración de la transcripción, el contexto colonial de su redacción (el papel europeo, el alfabeto latino, los préstamos cristianos) y su contenido vinculado con el saber médico ancestral.

En el interior de este marco sincrético y complejo encontramos una estructura narrativa propiamente autóctona. En primer lugar, el diálogo entre el terapeuta y las fuerzas sagradas responsables de las enfermedades representa de por sí una estructura. El modelo dialógico y las preguntas del hablante conforman un armazón muy frecuente en los cantos rituales del mundo mesoamericano (Sherzer y Woodbury, 1987: 7). En segundo lugar, se evidencia una estructura sintáctica, conceptual y rítmica propiamente indígena: las frases presentan una estructura paratáctica, sin una organización jerárquica de la información. El aspecto más evidente es la repetición de núcleos de significado, donde se reitera una parte de la frase en posición anafórica y varía un elemento, normalmente el sujeto o el complemento. El ritmo del texto no consiste sólo en un esquema de repetición de sonidos y significados. Desde el punto de vista semiótico, el ritmo es una 
forma dinámica substancial, que mueve el texto y sugiere posibles correlaciones (Sedda, 2006: 24).

En relación con el nacimiento de la enfermedad causada por la picadura de avispas, el terapeuta repite de manera obsesiva la genealogía de la enfermedad, que en la paleografía de Bolles y en mi traducción del maya sería:

Hija de Ix Kan Tamen Kin

Ix Kan Tanen u

hija dicen de Oo Tancas

hija dicen de Ah Ci Tancas

$[\ldots]$

hija como de Ix Uoh Ti Caan

Ix Uo Ti Munyal

hija dicen de Ix Kan Tanen Kin

Ix Kan Tanen U

hija dicen de Ix Coco Can

Ix Coco Munyal

[...]

hija como de Ix Uoh ti Caan

Ix Uoh ti Munyal

Ix Kan Tenen Kin

Ix Kan Tanen U

hija como de Ix Kan Dzul Mo

$[\ldots]$

hija de Ix Ko Caan

Ix Ko Munyal

hija dicen de Ah Ci Tancas

hija dicen de Ah Oo Tancas

$[\ldots]$

hija como de Ix Uoh ti Caan

Ix Uoh ti Munyal

hija como de Ix Kan Tenen Kin

Ix Kan Tanen U

hija de Ix Ko Caan

Ix Ko Munyal

hija de Ah Ci Tancas 
hija dicen de Oo Tancas

hija dicen de Ix Kan Dzulmo

$[\ldots]$

Hija como de Ix Uoh ti Caan

Ix Uoh ti Munyal

hija como de Ah Ci Tancas

hija dicen de Ah Oc Tancas

hija dicen de Ah Oo Tancas

hija dicen de Ix Kan Dzul Mo

$[\ldots]$

Hija dicen de Ah Ci Tancas

Oo Tancas

hija dicen de Ah Co Tancas

Kan Pet Kin Tancas

hija dicen de Ix Kan Tanen Kin

Ix Kan Tanen U

[...] (pp. 46-56).

La repetición constante y obsesiva de las frases a veces se rompe gracias a la variación de la estructura gramatical, con una ulterior profundización del significado. En el mismo texto, un poco más adelante, siempre en mi traducción, se afirma que:

Ix Kan Dzul Mo es su madre

hija dicen de Ix Kan Tanen Kin

Ix Kan Tanen U (p. 59).

Es evidente que la función principal de la letanía es producir un estado hipnótico en el paciente. En esto se puede apreciar la evidente función fática del texto ritual, ya que las repeticiones involucran y movilizan a los participantes en un mismo ritmo, creando comunión y produciendo una socialización del mensaje (Guiraud, 1996: 22).

Cabe señalar las múltiples implicaciones simbólicas de los dioses asociados en la estructura gramatical paralela del paso antes citado, indicados como origen y padres de la enfermedad. En sus nombres se evoca el poder regenerador del sol y de la luna, las respuestas que dan los glifos en el cielo y en las nubes, junto al carácter nefasto de la guacamaya, la locura y la enfermedad del caminante. El origen del malestar se mezcla con el poder fertilizador de los astros, hasta llegar 
a una coincidencia circular de las causas y la curación de los padecimientos. Al mismo tiempo, la repetición de la palabra can, "cuatro", también con la alusión a sus homófonos (caan, "cielo", can, "serpiente" y kan, "amarillo"), además de crear ecos sonoros por medio de la aliteración, evoca la extensión cuatripartita del espacio, la fertilidad celeste y el color amarillo asociado a la plenitud de la vegetación.

\section{El paralelismo}

El elemento retórico que más llama la atención en El ritual de los Bacabes y que se encuentra en las expresiones poéticas indígenas de distintas regiones y épocas, es el uso constante del paralelismo (Arzápalo, 1987: 14; Sherzer, 1990: 19). Este recurso rítmico y semántico funciona tanto a nivel macrotextual (en la repetición de conceptos, fórmulas y bloques de significado), como a nivel microtextual (en la reiteración de sonidos, morfemas y palabras) (Sherzer, 1990: 19). En particular, el paralelismo constituye la base de la versificación mesoamericana, o sea la reincidencia de unidades de significado en construcciones más o menos cerradas (Sherzer, 1990: 18). El esquema consiste en la repetición paralela de estructuras gramaticales o semánticas. Ambos niveles del paralelismo, el gramatical y el semántico, conforman los dos modelos principales de la versificación, que en la tradición maya es de tipo lógico-semántico.

La totalidad de los textos está formada por la sucesión de unidades de sentido, en las que se reiteran en paralelismo seis, siete o más versos con una estructura gramatical rigurosa, en las cuales varía un solo elemento, como en el siguiente ejemplo, en donde el padecimiento queda:

Macmac ti chuen

macmac ti munyal

macmac ti luum

macmac ti yikal

macmac ti kin

macmac ti akab

macmac ti tan

macmac tin pach

macmac ti hun suyi

u macmac che

$u d z o c$

Amen (p. 206).

Atrapado en Chuen

atrapado en las nubes

atrapado en la tierra 


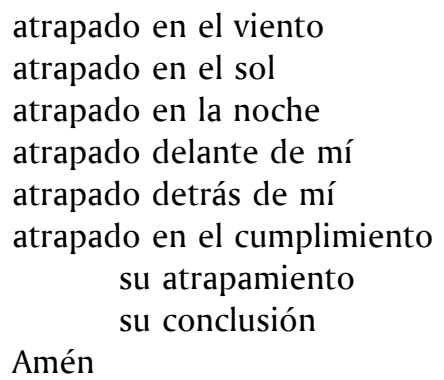

A través del paralelismo, se verifica una progresiva profundización de los significados, aludidos desde distintos puntos de vista. De esta manera, en la lucha contra la enfermedad se integran las fuerzas del cielo y de la tierra, el día y la noche, el calendario ritual junto al cuerpo del terapeuta. La estructura paralela vincula estos actores como si fuera un mismo sujeto que actúa contra los padecimientos humanos, en el centro del universo y del acto curativo.

En otros casos, el paralelismo gramatical es más flexible, ya que varían distintos elementos de la frase, pero se mantiene la estructura gramatical paralela:

Hunuc can ahau u kinil a sihic ceh yax cabe chac petan kin a yum te ti cane

yx hanil ek a na te ti cane

ix ho chan ek a na te ti cane

ix pic tzab a na te ti cane (p. 153).

Uno 4 Ahau es el día de tu nacimiento, cardenillo

el rojo sol redondo es tu padre, allá en el cielo

la límpida estrella es tu madre, allá en el cielo

las cinco pequeñas estrellas / serpiente son tu casa, allá en el cielo

los 8000 cascabeles son tu casa, allá en el cielo

El paralelismo ayuda a enfatizar los significados simbólicos atribuidos a los astros, cuando se afirma que en el cielo brillan las cinco pequeñas estrellas. Según el Diccionario Maya Cordemex (1980: 848), Chan Ek es el nombre que alude a la constelación de las Pléyades. Por la relación de homofonía de chan con la antigua forma con la cual se designaba la serpiente, otra traducción posible sería "estrellas serpiente", siempre en alusión a las Pléyades, aunque actualmente esta constelación se conoce en maya con el nombre de Tsaab. ${ }^{6}$

Como bien señala Chávez Guzmán, en El ritual de los Bacabes son evidentes las implicaciones astrales de ciertas enfermedades llamadas tancas o tamcaz (Chávez, 2013: 154). En la medicina maya colonial y actual, algunos vientos malignos que

${ }^{6}$ Miguel Óscar Chan Dzul e Irma Pomol Cahum, comunicación personal, 30 de mayo de 2020. 
causan el padecimiento son traídos precisamente por las Pléyades al salir del Inframundo, o sea después de su desaparición por su conjunción con el sol, aproximadamente entre el 3 de mayo y el 4 de junio y entre el 7 y el 25 de noviembre (Chávez, 2013: 154-162, 168). Con referencia al tipo de padecimiento llamado tancas, esta palabra según el pensamiento maya contemporáneo alude a una energía, un animal salvaje o "algo que provoca temor, shock en la persona" que lo mira. ${ }^{7}$ Cabe mencionar que el mismo término interviene en la composición de la palabra tamcazchee, planta medicinal usada para aliviar las enfermedades del mismo nombre (Chávez, 2013: 157-158; Calepino de Motul, 1995: 698). Este doble significado de las "estrellas serpiente" asociadas a las enfermedades y a las plantas medicinales se dilata en la línea siguiente en referencia a los cascabeles del cielo, sugiriendo por homofonía una identificación entre el cielo (caan) y la serpiente (can), y expandiendo su poder fertilizador.

El paralelismo tiene la función importante de dilatar la significación textual y crear una densidad semántica alrededor de los conceptos más importantes. A través del paralelismo, por un lado, se comunica la realidad desde variadas perspectivas, como si observáramos un objeto desde múltiples puertas de acceso; por otro, se produce una dilatación y una densidad de significados muy eficaces en los textos rituales (Sherzer, 1990: 19).

\section{Paralelismo semántico}

En el lenguaje de El ritual de los Bacabes se registra también la presencia de paralelismos semánticos, donde varía la estructura gramatical de dos o más líneas paralelas, pero se mantiene un nexo semántico entre los referentes. A pesar de la estructura gramatical libre, se verifica una progresiva profundización de los significados aludidos desde distintos puntos de vista. El sujeto y el verbo cambian, pero las frases mantienen una coherencia semántica y contribuyen a denotar el referente desde múltiples perspectivas.

Te dzoci u dzibtabal u pach lay chacal $x$ hun pedz kin lo

dzibtabi u na kin tu pach

hun pedzac u na kin

dzibtab tu pach hun pedz u na akab

ti dzibtab tu pach (pp. 85-86).

Se acabó allá la escritura de su espalda la de la roja Ix Hun Pedz Kin

fue escrita la Casa del día en su espalda

${ }^{7}$ Miguel Óscar Chan Dzul e Irma Pomol Cahum, comunicación personal, 30 de mayo de 2020. 
una fue la toma de la Casa del día

fue escrita en la espalda de Hun Pedz la casa de la noche

allí fue escrita en su espalda

En este ejemplo, se observa también otro recurso propio de la tradición oral, que se ha definido como "expansión aposicional", o sea la introducción de un concepto, la dilatación del mismo, hasta la conclusión y el cierre en una última frase que concluye la información (Thornton, 1992: 5).

A pesar de la imposible realización de un estudio pragmático de los efectos fónicos y prosódicos de la recitación oral, el análisis retórico nos permite comprender que el paralelismo gramatical y semántico tiene también funciones rítmicas, ya que crean un movimiento entre armonía y tensión dinámica. La reiteración de las ideas y sonidos se combina con la variación de palabras o estructuras gramaticales. De este modo, se crea una composición de efectos fónicos y semánticos integrados en una única estética verbal. El paralelismo funciona entonces sobre distintos planos, el fonético, el gramatical y el semántico (Sherzer y Woodbury, 1987: 2-4; Sherzer, 1990: 26-27).

\section{Los difrasismos}

A menudo las frases paralelas se rompen en difrasismos, que permiten una ulterior profundización de los referentes, articulando un paralelismo gramatical sobre uno léxico. La asociación léxica del difrasismo no representa nunca un recurso aislado, sino que se caracteriza como dilatación de significados dentro de una estructura paralela, como se puede ver en el siguiente ejemplo:

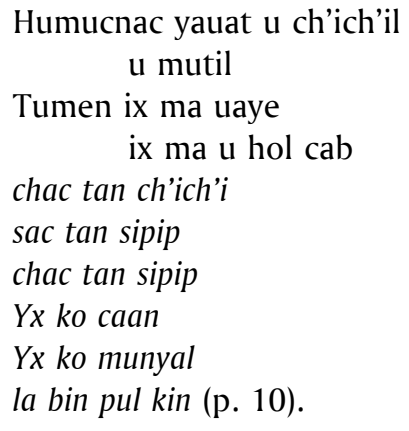

Resuena estruendosamente el grito de los pájaros de las aves

a causa de Ix Ma Uaye

Ix Mac Uhol Cab

los pájaros de pecho rojo

las aves de pecho blanco 
las aves de pecho rojo

Ix-papagayo-cielo

Ix-papagayo-nube

esto se dice que es el augurio anunciado

Cabe señalar que la tupida red de significaciones se extiende gracias a la polisemia de ciertas palabras; mut significa "ave, faisán", pero también "augurio, nueva, fama" (Calepino de Motul, 1995: 535; CORDEMEX, 1980: 542); ch'chi'il es "ave, pájaro" y también "ave agorera, augurio" (Calepino de Motul, 1995: 263; CORDEMEX, 1980: 134) y kin además de "sol, día, tiempo", significa también "nueva, fama" (Calepino de Motul, 1995: 424). La repetición de estas palabras polisémicas sugiere que hay otro significado detrás de la red aparente de los significantes.

A través de los difrasismos, la progresión cíclica de la narración se hace más compleja y se detiene; la acumulación léxica produce un cierto volumen semántico, que confiere una presencia concreta a la idea (Johansson, 2004: 68-69). La función más importante de los difrasismos es la de expresar el carácter complejo y dinámico de la realidad. Si tomamos como ejemplo el difrasismo ch'ab / akab, "la creación, la oscuridad", vemos que los dos elementos del par léxico desarrollan una unidad de significado y una complementariedad interna. El elemento masculino creador y el elemento femenino nocturno son al mismo tiempo aspectos autónomos e interdependientes de la concepción del universo como organismo múltiple y dinámico (Thompson, 2008: 358). Ambos elementos del difrasismo permiten la representación del mundo como un ser vivo en la relación entre sus partes constituyentes. A través del difrasismo, los referentes amplían su carga de significado, enfatizando su carácter estratificado. El universo se presenta entonces como el resultado de fuerzas de fertilización masculinas y femeninas y como principio de regeneración.

El modelo más frecuente de difrasismo es el binario, con pares léxicos muy frecuentes en la tradición poética maya de distintas latitudes, como "sangre / sangre cuajada", "brazo / pierna", "lanzas / flechas", "cielo / nubes", "sol / luna", "cuatro caminos / cuatro lugares de descanso", "abanico / bastón", "día / noche”, "árbol / maleza", "rojo / blanco", "dios $(k u)$ / Bacab", "arco de hierbas / maleza", "nacimiento / creación", "arco de hierbas / acantun", "dañar / arrebatar", "tu madre / tu padre", "hijo de mujer / hijo de hombre", "el hombre de madera / el hombre de piedra", "su loca creación / su loca oscuridad", "su creación celeste / su oscuridad celeste"; "loco hijo de mujer / loca oscuridad".

Sin embargo, abunda también el modelo ternario de asociación léxica, como "el tabaco rojo / el tabaco blanco / el tabaco negro" o "esta es tu madre/ esta es tu condición / este es tu padre" o también "sol / luna / estrellas". Pero el modelo que expresa la máxima dilatación semántica es el cuádruple, sobre todo con relación al espacio cuatripartito. Los ejemplos son numerosos y podemos mencionar: "Ixchel Roja / Ixchel Blanca / Ixchel Negra / Ixchel Amarilla" o "rojas hormigas / blancas / negras / amarillas hormigas". 
Aunque la forma más común en Mesoamérica es el difrasismo binario, las estructuras difrásticas de cuatro elementos no son raras en el área maya; la alusión al espacio en un difrasismo cuádruple abunda en los textos coloniales. Encontramos una mención en los Cantares de Dzitbalché, en el Cantar 11 (Barrera, 1980), y sobre todo en los documentos de tierras de Yucatán, ya que la repetición de palabras en una misma estructura gramatical implica una acción de demarcación del espacio que se lleva a cabo hacia el este, el norte, el oeste y el sur (Restall, 1997: 189).

\title{
Marcadores de discurso y recursos fonéticos
}

En las plegarias de El ritual de los Bacabes son muy usuales los marcadores de discurso, como can ("entonces, pues"), bin ("tal vez, se dice, dizque"), baca y bacan ("pues", "también, de manera que"), xan ("también, así como"), ix ("tal vez, acaso"), bacin ("cómo, cuándo, tal vez"), che y be che ("oh"), sam ("pronto"), tun (“ya, finalmente"). Estas partículas tienen una función retórica más que semántica y sirven para enfatizar los conceptos y subrayar las estructuras paralelas; son propias de las comunicaciones orales mayas yucatecas y se atestiguan desde la época colonial hasta la actualidad (Salomon, 1998: 625-634; Arzápalo, 1987: 13; Arzápalo, 1989: 380). Son muy frecuentes en las comunicaciones orales de distintos grupos americanos y a menudo tienen una función estilística y rítmica, al funcionar como marcadores del sistema de versificación (Sherzer, 1990: 18-23). Su papel es mucho más importante de lo que pueda apreciar un lector occidental, ya que constituyen un armazón que sustenta la estructura textual.

\author{
Yal bin Ix uoh ti caan \\ Yal bin Yx Culum Can \\ Yal bin Yx co pauah ek \\ Yal bin $Y x$ hun meklah \\ Yal bin $Y x$ hun sipit munyal \\ Yalix bin $Y x$ oc[om] tun $x i x$ \\ Yx ocom tun can (p. 69). \\ La hija dicen de Ix Uoh Ti Caan \\ La hija dicen de Ix Culum Can \\ La hija dicen de Ix Co Pauah Ek \\ La hija dicen de Ix Hun Meklah \\ La hija dicen de Ix Hun Sipit Munyal \\ La hija dicen de Yx Oc[om] Tun xix \\ Ix Ocom Tun Can
}

Como en muchos otros textos mayas coloniales, son abundantes también los recursos fonéticos (Hanks, 1989: 103), en particular la aliteración, la repetición 
de una palabra y el quiasmo. Es evidente que mi análisis sólo se pude basar en la transcripción alfabética del documento, sin poder tomar en cuenta los aspectos prosódicos, esenciales para un estudio exhaustivo de la realización fonética y de la performance del canto ritual. Sin embargo, aun considerando el carácter parcial de este estudio, la transcripción alfabética de los textos nos permite comprender la importancia de tales recursos, basados en la intensificación, la reiteración y la inversión del esquema rítmico.

Los juegos fonéticos no tienen sólo una función estética, sino también mnemónica y se encuentran con gran frecuencia en los textos de tradición oral formalizada. La repetición de sonidos y de palabras permite una más eficaz memorización del texto oral y también una mejor comprensión por parte del público (Zumthor, 1982: 123-125; Ong, 1991: 22-23). En el siguiente ejemplo es evidente el juego de palabras entre conceptos afines y la variación de las raíces verbales:

\author{
Ci bin yalabal lae \\ $\mathrm{Cu}$ than ti yol caan uaye (p. 17). \\ se dice que esto es dicho \\ lo dice en el corazón del cielo, aquí
}

La aliteración es un recurso casi omnipresente en el documento, ya que facilita su memorización, además de crear estados hipnóticos en el oyente. Sin embargo, otra función importante a mi parecer es la enfática, ya que los nudos semánticos más importantes son resaltados por medio de la repetición obsesiva de sonidos, como en el siguiente ejemplo, donde he señalado la aliteración en negritas:

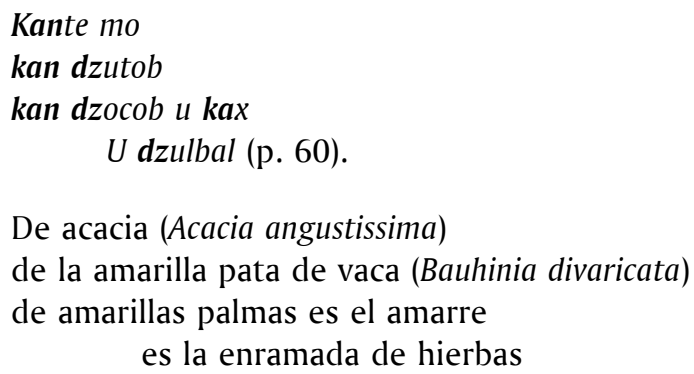

La importancia de este paso consiste en la prescripción de las plantas medicinales necesarias para curar la enfermedad tratada en el ensalmo. El amarre del arco de flores parece ser un acto ritual de sujeción de las enfermedades junto al manojo de hierbas. La línea siguiente, en efecto, usa una aliteración, marcada en negritas, al decir de la enfermedad:

U kasic tan chacal chakan (p. 60).

Es su derrota en medio del campo rojo 
A través del uso de las plantas medicinales enfatizadas por la aliteración, el paciente logrará derrotar la enfermedad en el campo asociado al este. Cabe señalar que tanto esta dirección cardinal como el arco o la enramada de hierbas, dzulbal, de las líneas anteriores, se relacionan con ceremonias de regeneración, nacimientos y gestación, propiciando la recuperación del enfermo (Landa, 1986: 64-67). Además, en la última línea, sigue el juego fonético de las aliteraciones entre las palabras chacal y chakan.

En algunos casos, se observa una repetición de un mismo morfema, de una raíz verbal o nominal dos, tres o cuatro veces, posiblemente con una función intensificadora (Arzápalo, 1987: 15). Este recurso se encuentra muy frecuentemente en otros textos literarios mayas posiblemente de la misma época, como los Cantares de Dzitbalché (Nájera, 2007), tanto que se puede considerar como una característica del estilo ritual maya yucateco colonial, como se puede ver en el siguiente recurso, indicado en negritas.

\title{
La tun bacin tin siscunci u kinam \\ Yax am te \\ Yam am tun \\ Am am am am \\ Amen (p. 160).
}

\author{
Así es como ya he enfriado su ponzoña \\ primera araña de madera \\ primera araña de piedra \\ araña araña araña araña \\ Amén
}

En este texto ritual para curar la picadura de la araña venenosa, el terapeuta juega con las palabras. Kinam es una palabra polisémica, relacionada con kin, "sol, calor"; kinam indica "fuerza, ponzoña", pero también "dolor leve" (Yoshida: 2009: 321). Se refiere al calor de ciertos objetos, plantas, animales o personas que pueden enfermar, pero también curar. La idea está relacionada al tonalli de la cultura náhuatl (Chávez, 2006: 121). El terapeuta enfría el excesivo calor y el dolor causado por el piquete, apagando su veneno. Pero el término am indica la causa y también la solución del padecimiento, ya que la palabra am designa la araña y al mismo tiempo unas piedritas o cuentas usadas para hacer adivinaciones en el ámbito médico, como nos informa Landa en su Relación (Landa, 1986: 93). En el texto para las picaduras de araña, el sacerdote afirma u uayasaba u pach yax am te / yax am tun, "es el símbolo detrás de la verde araña (cuenta) de madera / de la verde araña (cuenta) de piedra" (pp. 157-160).

En algunos casos, la repetición de sonidos es tan intensa que crea efectos onomatopéyicos, como en el siguiente ejemplo, donde la aliteración tiene quizás 
la función de enfatizar el nombre de la planta medicinal macal, conocida también como "malanga" (posiblemente Xanthosoma violaceum; Roys, 1976: 262).

Macal, sin ni ni ni, tzin ni ni ni tzin (p. 198-199).

La repetición de los morfemas reproduce por onomatopeya el sonido de un arco, mencionado en la línea anterior, tal vez símbolo e instrumento de curación. Cabe señalar también que el arco, chulul, es una palabra homófona de otra planta, la Aploplanesia paniculata (Roys, 1976: 239) posiblemente usada para la construcción del arma.

También el quiasmo, o sea la inversión del orden de las palabras en dos expresiones paralelas, es muy abundante y parece ser un recurso muy difundido en el área maya (Christenson, 1988). No sólo permite la variación dentro de la estructura paralela, sino que a mi parecer tiene una función enfática y focalizadora. Crea una inversión de ideas y de sonidos, produciendo una variación en el esquema gramatical que llama la atención. Se asocia especialmente a contextos de creación y regeneración, como en el siguiente paso, donde he marcado en negritas este recurso:

\author{
U coil tan cas lae \\ Hun can ahau u kinil \\ Hun can ahau u yakbilil \\ U coil akab \\ $U$ coil kin (p. 44). \\ Su loco delirio es este \\ Uno 4 Ahau es su día \\ Uno 4 Ahau es su noche \\ su loca noche \\ su loco día
}

Asimismo se nota la combinación de la aliteración indicada con negrita con una estructura quiástica en la inversión del orden día / noche - noche / día y también una asociación con la regeneración. El quiasmo se verifica entre las piedras y los postes destinados a recoger sangre sacrificial ubicados en las cuatro entradas del pueblo en ocasión de ceremonias de renovación, como se puede apreciar en el ejemplo marcado en negritas:

\author{
Hunten hi hutcabal \\ hunten hix chuen \\ tume hunten acantun \\ acante \\ hu tah kik tu pacha acante \\ acantun (p. 89).
}


Una vez sea arruinado

una vez sea armado

a causa por una vez del acantun

del acante

una rajadura / cantidad de sangre en la parte posterior del acante

del acantun

\section{Las fórmulas}

Como expresión propia de las comunicaciones orales formalizadas, estos textos rituales se construyen alrededor de fórmulas recurrentes en el mismo texto y también en diferentes plegarias, dando coherencia y facilitando su memorización (Ong, 1991: 20-23; Zumthor, 1982: 122-124). Las dos líneas isotópicas principales de las fórmulas son la interpretación de los símbolos y la indagación sobre el origen de la enfermedad y su cura. En el caso de la isotopía de la lectura simbólica podemos mencionar fórmulas como: "se dice que es dicho", "pues se dice que es la palabra de los glifos, pues se dice que es su respuesta”, o también "¿Cuál es su pájaro / cuál es su ave (o su presagio)?" "¿Cuál es pues su símbolo?”, "este pues es su símbolo", de uayasba, "figura, opinión, parábola y señal", término constantemente asociado a la lectura de presagios y de augurios (Calepino de Motul, 1995: 746; CORDEMEX, 1980: 917). La segunda línea semántica comprende fórmulas como: “¿Quién es su árbol / su maleza?”, y también “¿Quién es su madre? ¿Quién es su creador? ¿Quién es tu padre?", repetidas muchas veces en el documento.

\section{Paronomasia e incorporación del saber medicinal en el lenguaje sagrado}

El último recurso que quisiera destacar es la paronomasia, o sea la relación entre palabras homófonas, pero de distinto significado. El sacerdote explota la red de significación de las palabras con significantes afines, para sugerir una relación de significado. Este recurso es muy utilizado en el lenguaje ritual maya, y también en las adivinaciones contemporáneas donde el adivino explora todos los posibles significados de las palabras fonológicamente afines al signo calendárico considerado (Tedlock, 1981).

En El ritual de los Bacabes la paronomasia tiene un papel esencial a la hora de relacionar enfermedades con animales y plantas medicinales aptas para su curación, por medio de la relación fonética de sus significantes. Algunos remedios vegetales son declarados abiertamente, pero en ciertos casos la revelación del tipo de planta es críptica, a través de una relación de paronomasia. Se trata posiblemente de la revelación de las "verdaderas plantas medicinales" y del conocimiento profundo de las técnicas de curación, destinadas a los iniciados. Están consignadas sólo a los que tienen el don de la sanación, a los terapeutas que logran pasar por el umbral de los otros mundos y recibir allí las respuestas de 
los símbolos (Hirose, 2018: 122). Los nombres de las "verdaderas plantas” están escondidos en la malla retórica del texto, a través de relaciones semánticas que sólo el iniciado puede decodificar. La indicación botánica es sugerida precisamente por paronomasia a través de la referencia a los animales o las enfermedades homófonas.

La importancia de esta revelación es evidente, ya que repetidas veces se pregunta a las enfermedades personificadas: “¿Cuál es tu símbolo?”, “¿Quién es tu árbol, tu hierba?” o también “¿Quién es tu enramada de hierbas?” (pp. 1, 5, 31, 33, 48, 73, 87, 103, etc.). En estos casos, en mi opinión, se alude, por un lado, al árbol asociado al rumbo cósmico, y por otro, a la hierba curativa involucrada en el nombre mismo de la enfermedad. La revelación de la planta medicinal es esencial para erradicar el padecimiento. Lo declara abiertamente el terapeuta cuando afirma: $u$ lubul bin tan yol che / tan yol aban, "su caída dicen que es entre los árboles / entre la maleza” (p. 111).

En El ritual de los Bacabes las plantas parecen personificadas; en algunos casos también son consideradas antepasados humanos, como parece haber ocurrido en el pensamiento prehispánico (Emboden, 1983: 94). Casi siempre están asociadas a los prefijos femeninos o diminutivos / despectivos $-i x$ / $-x$ (Roys, 1965: XIII). A través de esta personificación, notamos una extensión de la categoría humana a las plantas, así como una convergencia de hombres y vegetales en el mismo ciclo vital. En algunas prácticas terapéuticas mayas contemporáneas se dibuja el perfil del pie del paciente sobre el tronco de una planta, que funciona como su representación metonímica, su extensión y su sustituto (Hirose, 2014: 59); también son frecuentes las menciones a actos curativos que comprenden la comunicación con las plantas, en particular con especies en las que el terapeuta confía (Doemel, 2013: 6).

Un aspecto muy interesante reside en la relación, por medio de la paronomasia, entre la planta medicinal, el nombre de la enfermedad, su causa o la parte del cuerpo afectada, como en el texto ritual para la curación de las convulsiones causadas por el piquete de la tarántula, U thanil chiuoh kak / chiuoh tancas, "las palabras de la tarántula de fuego / el delirio de la tarántula” (pp. 32-33). Tancas o tancaz son contracciones de tamacaz, padecimiento asociado a delirios, estados febriles y daños anímicos (Chávez, 2013: 145). La palabra chiuoh indica a la tarántula y también el nombre del malestar por su piquete (CORDEMEx, 1980: 102); en combinación con kak, "fuego", además alude a la planta medicinal chiuoh kak (Stenorhynchos orchioides), en forma de araña, cuya raíz es usada para la curación de la gangrena (Bolles, 1997: s.p.). Por último, quisiera mencionar que el nombre de la tarántula se asociaba también a una constelación, la del Alacrán del Viejo Mundo, por lo menos en las estrellas de la cola final, con implicaciones astrales nefastas, asociadas a las enfermedades (Chávez, 2013: 166).

Las alusiones paronomásticas a las plantas son múltiples. Más adelante el terapeuta afirma: 


\author{
Bax u dzulbal? \\ Chiuoh xiu \\ sacal koch u dzulbal \\ chac tan xacat be \\ sac tan xacatbe u ch'ch'il (pp. 32-33). \\ ¿Cuál es su enramada de hierbas? \\ La hierba de la tarántula \\ la blanca higuerilla es su enramada \\ xacat be con el pecho rojo \\ xacat be con el pecho blanco es su pájaro / augurio
}

Xacat be es un insecto parecido al chapulín (Roys, 1976: 341), pero la raíz xac interviene en la definición de varias plantas, Dipholis salicifolia, Byrsonima crassifolia o Boerhaavia erecta (Bolles, 1997: s.p.). En definitiva, la enramada sugerida como augurio contiene referencias paronomásticas a los síntomas de la enfermedad, la causa (la tarántula) y una serie de hierbas medicinales sugeridas en las líneas paralelas.

En el texto para la curación de las encías (pp. 172-173), titulado $U$ thanil chac nich' max, "las palabras de las rojas encías mono", y en una receta medicinal registrada en las páginas 220-221, vemos otra vez la red conceptual que une enfermedad y plantas medicinales. Nich' significa "encías y dientes" (Calepino de Motul, 1995: 561; CORDEMEX, 1980: 568), mientras que max significa "mono" (Calepino de Motul, 1995: 515; CORDEMEX, 1980: 497), pero la unión de las dos palabras alude a una planta medicinal anonácea, llamada nich' ma'ax che', Uvaria campechianus, usada para curar la inflamación de las encías (CORDEmex, 1980: 569).

El prefijo chac también tiene distintos significados; por un lado alude al color de la inflamación, por otro podría indicar la gravedad de la enfermedad, con un uso ya presente en los códices (Thompson, 1958: 304). En fin, esta expresión parece referirse a otra hierba, llamada chac nich' max, Tournefortia volubilis, también apta para la sanación de erupciones e inflamaciones bucales (Roys, 1976: 231). Con una sola expresión se sugieren entonces dos hierbas medicinales, la parte del cuerpo afectada, la gravedad de la enfermedad y la relación con el animal, no sólo por sus implicaciones simbólicas.

Las relaciones de paronomasia entre la enfermedad, los elementos simbólicos y las plantas son múltiples, como se nota en la plegaria $U$ thanil Ah Oc Tancas, "Las palabras para el delirio del pie / del caminante", donde hay una explosión paronomástica relacionada con la palabra $o c$, "pie, andante, caminante, alguien que anda cojo"; oc también es una raíz verbal que significa "plantar, sembrar" (Bolles, 1997: s.p.), que interviene en la definición de algunas plantas medicinales, en particular Morinda Yucatanensis greenman —conocida como x-hoyoc, hoyoc, hooyoc, xhoyoc, xoyencab o jo'oyo y usada con funciones antibacteriana, antiinflamatoria y para mejorar la circulación y el decaimiento-, o también la puluxtakoc, o sea Urvillea Ulmácea, usada en ámbito medicinal (Bolles, 1997: s.p.). 
De igual manera se pueden señalar las menciones de coc, "asma" (pp. 64-82), que interviene en el nombre de muchas plantas, entre las cuales figuran unas plantas curativas como Croton Glabellus, útil para el asma, la tisis, padecimientos de los testículos y abscesos en la garganta, y es homófona de $c o c$, "pequeña tortuga" (Bolles, 1997: s.p.), cuyas partes del cuerpo todavía hoy son prescritas en Yucatán como remedio alimenticio para curar enfermedades de las vías aéreas. ${ }^{8}$

También el uso polisémico de la palabra tok (pedernal) es muy significativo. En el rezo por el nacimiento del pedernal (pp. 183-185), el terapeuta pregunta: Mac u che?, “icuál es tu árbol?". La respuesta que se da es: chacal x tok aban u dzulub tok, "roja la hierba / la maleza pedernal, su enramada pedernal". El significado oscuro se aclara al considerar que tok aban se refiere a dos plantas, Trixis radialis y Eupatorium odoratum, mientras que dsulub tok es un tipo de orquídea, Bauhinia divaricata (Bolles, 2003: 113), prescrita para fiebre, disentería, pleuritis e hinchazones (Roys, 1976: 315).

Siempre con un significado figurado se usa la palabra tok en otro texto curativo para definir un tipo de viruela, kak akab tok, "fuego noche pedernal" (p. 230), posiblemente también en alusión a una especie botánica (Bolles, 2003: 139). Cabe mencionar que en el texto para la curación de las muelas (pp. 162-164), la misma palabra, en asociación con el color rojo, sugiere una planta usada específicamente para aliviar la inflamación de la garganta (Bolles, 1997: s.p.). De la misma manera, unas líneas más abajo, el caracol, hub, que aparece aquí asociado al color negro, alude a una planta llamada $e k$ hub, "caracol negro", Zea mays (Bolles, 1997: s.p.; 2003: 105). Asimismo, en un texto para la curación de otra forma de viruela llamada bat aban kak (p. 225), "fuego, erupción cutánea bat aban", el mismo nombre alude a una planta medicinal nombrada precisamente bat aban (Bolles, 2003: 137).

En la plegaria pronunciada por las infecciones de la piel (p. 101), las dos definiciones, chac mulah kak y chac muclah kak, se refieren tanto al herpes o fuego de san Antonio como a las hierbas medicinales aptas para curarlo (Bolles, 2003: 71). De la misma manera, el rezo titulado $U$ pedzil $x$ chac anal kak, "la trampa del rojo anal chak" (p. 106), alude con este nombre a la misma enfermedad cutánea y a la hierba medicinal homófona sugerida para su curación (CORDEMEX, 1980: 16).

En algunos casos las palabras que indican colores no se refieren sólo a los rumbos cósmicos, sino que indican también por homofonía, o sea asimilación de los significantes, especies distintas de una misma familia, por ejemplo, catzim, "Acacia gaumeri"; chac catzim, "rojo catzim, Acacia riparioides"; zac catzim, "blanco catzim, Mimosa bahamensis y Mimosa hemiendyta"; box catzim, "negro catzim, Mimosa"; catzim ek, "negro catzim, Prosopis chilensis". Lo mismo ocurre con la Plumeria (nicte) que se diferencia en especies según el prefijo que indica el color: chac nicte, zac nicte, zabac nicte, kan nicte (Bolles, 2003: IV). También en estos

\footnotetext{
${ }^{8}$ Irma Pomol Cahum, comunicación personal, junio 2019.
} 
casos, un saber concreto relativo a las plantas medicinales se entrelaza con las configuraciones simbólicas del espacio cuadripartito, contribuyendo a una lectura a la vez física y metafísica de la enfermedad y sus remedios.

Aun en las sanaciones contemporáneas a menudo se usan los colores de las plantas por su correspondencia con el color del padecimiento, como las flores o plantas rojas para aliviar quemaduras de la piel o padecimientos de la sangre, así como las amarillas para curar problemas del hígado y el pus (Doemel, 2013: 6). De la misma manera, a veces se usan plantas que tienen forma parecida al órgano afectado, por ejemplo la Godmania aesculifolia para la expulsión de la placenta por su parecido con el cordón umbilical (Doemel, 2013: 6). Aquí también se nota que, como en el caso de la paronomasia, el principio básico de la curación es la correspondencia y la extensión de propiedades por analogía, como en muchos otros remedios que recrean la parte del cuerpo y el padecimiento que la afecta (Chávez, 2013: 408).

\section{Conclusiones}

El espacio textual funciona, como otros productos culturales, por medio de constantes infracciones. En esto reside su retórica textual, o sea en un mecanismo de infracciones con respecto al nivel no retóricamente codificado de la lengua estándar (Vjaceslav et al., 2006: 126-127).

A raíz del análisis de los sistemas de construcción de sentido del texto, ha sido posible restituir a los textos médicos su polivalencia semántica, centrando el análisis en los códigos y los modos de significación (Guiraud, 1996: 105). En cuanto sistemas semióticos, las plegarias de El ritual de los Bacabes no pueden ser considerados sólo mecanismos de transmisión de la información, sino como dispositivos de elaboración de nuevas informaciones (Salvestroni, 1985: 33-34).

Los textos rituales conforman un sistema modelizante secundario, un sistema que intenta reconstruir un modelo del mundo con base en un modelo primario, el linguíístico. El análisis de los mecanismos retóricos ha evidenciado que funcionan como núcleos de producción de sentido de múltiples capas, a nivel fonético, semántico y gramatical. El estudio de la organización discursiva ha permitido identificar leyes internas al texto y un sistema de correspondencias entre los distintos núcleos de significación. Se revelan en esto en cuanto estructuras o sistemas dinámicos de relaciones internas (Sedda, 2006: 51).

Como se ha propuesto por el enfoque semiótico, en la base de la organización discursiva de El ritual de los Bacabes encontramos el principio de la simetría / asimetría y el de intercambio periódico de alto y bajo. Estos dos principios se traducen en la ciclicidad (simetría) y en el desarrollo lineal (alto-bajo). Se habla de simetría y asimetría porque, para que haya comunicación, las figuras tienen que ser iguales y distintas, especulares, pero no idénticas, ya que cambia el orden. La ley de la simetría es la base del funcionamiento de los mecanismos generado- 
res de sentidos (Lotman, 1985: 74-76). En el lenguaje de El ritual de los Bacabes la simetría / asimetría se realiza en el paralelismo, la versificación semántica, la organización paralela del difrasismo y la reiteración de sonidos, fórmulas y estructuras gramaticales. Dentro de la categoría del intercambio periódico de alto / bajo y del desarrollo de la información, cabe mencionar la recurrencia de la paronomasia, que crea líneas de dilatación semántica y conexiones entre campos léxicos y movimientos en la significación textual, línea tras línea.

Todos los recursos retóricos analizados, la paronomasia, la versificación y las figuras fonéticas, funcionan como medios de conexión conceptual, ya que enfatizan las relaciones entre las ideas y producen por mimesis sonora el contagio semántico (Johansson, 2004: 66). También garantizan la memoria del colectivo y transforman datos caóticos, como el desequilibrio causado por la enfermedad, en un sistema significativo. Por lo que se refiere a su función de creador de significados nuevos, el texto no es un canal pasivo de transmisión de informaciones. Al contrario, en cuanto "congenio pensante" transforma profundamente el contenido a través de la connotación retórica (Lotman, 1985: 251-253).

El análisis del lenguaje en El ritual de los Bacabes ha puesto en evidencia que a través del proceso de "figurativización", u organización de figuras del discurso (paralelismos, versificación, difrasismos, aliteraciones, quiasmos, paronomasias), se pone en marcha el potencial de significación del texto, tanto en la configuración de una estructura profunda, como en la organización de esquemas discursivos (Solís, 2009: 118-124). Por último, quisiera destacar que el análisis retórico y semiótico realizado ha permitido apreciar el concepto de saber como una red, que no tiene centro, sino una serie infinita de interconexiones (Gherlone, 2013: 8-13).

\section{Bibliografía}

Arzápalo, Ramón

1987 “Introducción”, El ritual de los Bacabes. México: Universidad Nacional Autónoma de México, Instituto de Investigaciones Filológicas.

1989 "El lenguaje esotérico y literario de don Joan Canul en el Ritual de los Bacabes", Tlalocan, XI: 375-394. DoI: http://dx.doi.org/10.19130/iifl.tlalocan.1989.135.

2004 "El lenguaje del poder entre los antiguos mayas", La palabra florida: la tradición retórica indígena y novohispana, pp. 83-93, Helena Beristáin y Gerardo Ramírez Vidal (eds.). México: Universidad Nacional Autónoma de México, Instituto de Investigaciones Filológicas.

Barrera Vázquez, Alfredo

1980 "Libro de los Cantares de Dzitbalché”, Literatura maya, pp. 342-388, Mercedes de la Garza (ed.). Caracas: Ayacucho.

Bolles, David

1997 Combined Dictionary-Concordance of the Yucatecan Mayan Language. Disponible 
en: <http://www.famsi.org/reports/96072/m/miz_kaax_mokoy.htm> [consultado el 18 de mayo de 2019].

2003 A Translation of the Edited Text of Ritual of the Bacabs. Lancaster: Labyrinthos.

Calepino de Motul

1995 Ramón Arzápalo (ed.). México: Universidad Nacional Autónoma de México, Instituto de Investigaciones Antropológicas.

Cocom Pech, Jorge Miguel

2004 "Retórica en los libros del Chilam Balam de Chumayel y del Chilam Balam de Tuzik", La palabra florida: la tradición retórica indígena y novohispana, pp. 7382, Helena Beristáin y Gerardo Ramírez Vidal (eds.). México: Universidad Nacional Autónoma de México, Instituto de Investigaciones Filológicas.

CORDEMEX

1980 Diccionario Maya Cordemex. Alfredo Barrera Vásquez (ed.). Mérida: CORDEmeX.

Corominas, Joan

1987 Breve diccionario etimológico de la lengua castellana. Madrid: Gredos.

Corripio, Fernando

1984 Diccionario etimológico de la lengua española. México: Ediciones B.

Chávez Guzmán, Mónica

2006 "El Sol como fundamento curativo de las terapias mayas yucatecas en el período colonial”, Estudios de Cultura Maya, XXVIII: 121-139. DoI: http://dx.doi. org/10.19130/iifl.ecm.2006.28.615.

2013 Cuerpo, enfermedad y medicina en la cosmología maya del Yucatán colonial. México: Universidad Nacional Autónoma de México.

Chilam Balam de Ixil

2011 Laura Caso (ed.). México: Instituto Nacional de Antropología e Historia, Consejo Nacional para la Cultura y las Artes.

Chilam Balam de Kahua

s.f. Copia fotostática en poder de la autora.

Chilam Balam de Tuzik

1981 México: Grupo Dzíbil.

Christenson, Allen

1988 "The Use of Chiasmus by the Ancient Maya-Quiche", Latin American Indian Literatures Journal, IV (2): 125-150.

Chuchiak, John

2010 "Writing as Resistance: Maya Graphic Pluralism and Indigenous Elite Strategies for Survival in Colonial Yucatan, 1550-1750", Ethnohistory, LVII (1): 87116. DoI: https://doi.org/10.1215/00141801-2009-055. 
Denny, Peter

1991 "El pensamiento racional en la cultura oral y la descontextualización escrita”, Cultura escrita y oralidad, pp. 95-126, Don Olson y Nancy Torrance (eds.). Barcelona: Gedisa.

Doemel, Kaylee

2013 "Mayan Medicine: Rituals and Plant Use by Maya Ah-Men”, tesis de licenciatura en Arqueología. La Crosse: University of Wisconsin.

El ritual de los Bacabes

1987 Ramón Arzápalo (ed. y trad.). México: Universidad Nacional Autónoma de México, Instituto de Investigaciones Filológicas.

Emboden, William

1983 "The Ethnobotany of the Dresden Codex with Especial Reference to the Narcotic Ninphae Ampla", Botanical Museum Leaflets, 29 (2): 87-134.

Ferrari Bravo, Donatella

1975 "Sistemi secondari di modellizzazione”, Semiotica e cultura, pp. XI-LXXIX, Jurij Lotman y Boris Uspenskij (eds.). Milán: Ricciardi Editore.

García Ruiz, Jesús

1992 "El misionero, las lenguas mayas y la traducción: nominalismo, tomismo y etnolinguíística en Guatemala", Archives des Sciences Sociales des Religions, 77: 83-110.

Garza, Mercedes de la

2008 El legado escrito de los mayas. México: Fondo de Cultura Económica.

Gherlone, Laura

2013 La cultura fra alterità e complessità. La lezione di Jurij M. Lotman, tesis de doctorado en Ciencias de la Comunicación. Roma: Università La Sapienza.

Gubler, Ruth

2014 Yerbas y hechicerías del Yucatán. Izamal: Secretaría de Educación del Gobierno del Estado de Yucatán, Universidad Nacional Autónoma de México.

Guiraud, Pierre

1996 La semiología. México: Siglo XXI.

Hanks, William

1989 "Elements of Maya Style", Word and Image in Mayan Culture, Explorations in Language, Writing and Representation, pp. 92-111, William F. Hanks y Don S. Rice (eds.). Salt Lake City: Universidad de Utah.

2010 Converting Words. Maya in the Age of the Cross. Berkeley: Universidad de California.

Hirose, Javier

2008 "El ser humano como eje cósmico: las concepciones sobre el cuerpo y la 
persona entre los mayas de la región de los Chenes, Campeche”, tesis de doctorado en Estudios Mesoamericanos. México: Universidad Nacional Autónoma de México.

2014 "La noción de enfermedad y los principios de la terapéutica en la medicina tradicional maya: su aplicación en los problemas de salud de la sociedad contemporánea”, Memoria de la Cátedra Alfonso Barrera Vásquez, pp. 47-64, Lázaro Tuz y Javier Hirose (eds.). Valladolid: Universidad de Oriente.

2018 "La medicina tradicional maya: ¿un saber en extinción?, Trilce, LXXIV: 114134. DoI: http://dx.doi.org/10.22134/trace.74.2018.174.

Jakobson, Roman

1963 Essais de linguistique genérale. Paris: Minuit.

Johansson, Patrick

2004 "Retórica náhuatl o la teatralidad del verbo", La palabra florida: la tradición retórica indígena y novohispana, pp. 57-72, Helena Beristáin y Gerardo Ramírez Vidal (eds.). México: Universidad Nacional Autónoma de México, Instituto de Investigaciones Filológicas.

Karttunen, Frances

1998 "Indigenous Writing as a Vehicle of Postconquest Continuity and Change in Mesoamerica", Native Traditions in the Postconquest World, pp. 421-447, Elizabeth Hill Boone y Tom Cummins (eds.). Washington: Dumbarton Oaks.

Landa, fray Diego de

1986 Relación de las cosas de Yucatán. México: Porrúa.

Libro de Chilam Balam de Chumayel

1988 Mercedes de la Garza (ed.). México: Secretaría de Educación Pública.

Lockhart, James

1998 "Three Experiences of Culture Contact: Nahua, Maya, and Quechua”, Native Traditions in the Postconquest World, pp. 31-53, Elizabeth Hill Boone y Tom Cummins (eds.). Washington: Dumbarton Oaks.

Lotman, Jurij

1985 La semiosfera. Venecia: Marsilio Editori.

Martel Díaz-Cortés, Patricia

2004 "La magia de la palabra en El ritual de los Bacabes", Arqueología Mexicana, LXXIX: 34-39.

Morales Damián, Manuel Alberto

2006 "Espacio, tiempo y creación en el Ritual de los Bacabes", Construyendo cosmologías: conciencia y práctica, pp. 59-67, Gustavo Aviña y Walburga Wiesheu (eds.). México: Instituto Nacional de Antropología e Historia. 
Nájera Coronado, Martha Ilia

2007 Los Cantares de Dzitbalché en la tradición religiosa mesoamericana. México: Universidad Nacional Autónoma de México, Instituto de Investigaciones Filológicas.

Nájera Coronado, Martha Ilia y Manuel Alberto Morales Damián

2009 "Rituales de paso en las historias sagradas de los mayas: conocimiento y poder", Ritos de paso. Arqueología y antropología de las religiones, vol. III, pp. 233-255, Patricia Fournier, Carlos Mondragón y Walburga Wiesheu (eds.). México: Instituto Nacional de Antropología e Historia.

Ong, Walter

1991 Orality and Literacy. Londres y Nueva York: Routledge.

Restall, Matthew

1997 The Maya World Yucatec Culture and Society, 1550-1850. Stanford: Universidad de Stanford.

Ricoeur, Paul

1980 La metáfora viva. Madrid: Europa.

Ritual of the Bacabs

s.f. Manuscrito C0744.01, Garrett-Gates Mesoamerican Manuscripts, núm. 1, Princeton: Princeton University. Disponible en: <https://catalog.princeton. edu/catalog/3473501\#view> [consultado el 15 de mayo de 2019].

Rodríguez, Lizbeth Mercedes

2012 "De enfermedades y remedios: la transmisión oral de uso doméstico de plantas con fines medicinales en Campeche, México", Apuntes. Revista de Estudios sobre Patrimonio Cultural, XXV (1): 62-71.

Roys, Ralph

1965 Ritual of the Bacabs. Norman: Universidad de Oklahoma.

1976 The Ethno-Botany of the Maya. Philadelphia: Institute for Study of Human Issues.

Salomon, Julie

1998 "Marcadores de discurso en estructuras paralelas en la literatura oral de los mayas yucatecos contemporáneos", Memoria del Tercer Coloquio Internacional de Mayistas, vol. II, pp. 624-643, Mercedes de la Garza et al. (eds.). México: Universidad Nacional Autónoma de México, Instituto de Investigaciones Filológicas.

Salvestroni, Simonetta

1985 "Nuove chiavi di lettura del reale alla luce del pensiero di Lotman e dell'epistemologia contemporanea", La semiosfera, pp. 7-46, Jurij Lotman (ed.). Venecia: Marsilio Editori. 
Sedda, Franciscu

2006 "Imperfette traduzioni”, Tesi per una semiotica delle culture, pp. 7-68, Yurij Lotman (ed.). Roma: Meltemi.

Sherzer, Joel

1990 Verbal Art in San Blas. Cambridge: Universidad de Cambridge.

Sherzer, Joel y Anthony Woodbury

1987 "Introduction", Native American Discourse. Poetics and Rhetoric, pp. 2-9, Joel Sherzer y Anthony Woodbury (eds.). Cambridge: Universidad de Cambridge.

Sidorova, Ksenia

2000 "Lenguaje ritual. Los usos de la comunicación verbal en los contextos rituales y ceremoniales”, Alteridades, X (20): 93-103.

Siméon, Rémi

1996 Diccionario de la lengua náhuatl. México: Siglo XXI.

Solís Zepeda, María Luisa

2009 "Notas sobre la relación entre retórica y semiótica a propósito del problema de la figurativización”, Las figuras del texto, pp. 111-125, Helena Beristáin y Gerardo Ramírez Vidal (eds.). México: Universidad Nacional Autónoma de México.

Tedlock, Barbara

1981 "Quiché Maya Dream Interpretation”, Ethos, 9 (4): 325-329.

Thompson, Eric

1958 "Symbols, Glyphs and Divinatory Almanacs for Diseases in the Maya Dresden and Madrid Codices", American Antiquity, XXIII (3): 297-308. DoI: https://doi. org/10.2307/276312.

2008 Historia y religión de los mayas. México: Siglo XXI.

Thornton, Agatha

1992 The Story of Mai by Te Rangik heke. Christchurch: Universidad de Canterbury.

Vjaceslav, Ivanov, Jurij M. Lotman, Aleksandr Piatigorskij, Vladimir N. Toporov y Boris A. Uspenskij

2006 “Tesi per un'analisi semiotica delle culture”, Tesi per una semiotica delle culture, pp. 107-147, Yurij Lotman (ed.). Roma: Meltemi.

Yoshida, Shigeto

2009 "Conceptos fisiológicos sobre las enfermedades de los mayas yucatecos: un análisis taxonómico de vocablos en los diccionarios coloniales en lengua maya", Text and Context: Yucatec Maya Literature in a Diachronic Perspective, pp. 313-334, Antje Gunsenheimer, Tsubasa Okoshi y John F. Chuchiak (eds.). Aachen: Shaker Verlag. 
Zumthor, Paul

1982 Introducción a la poesía oral. Madrid: Taurus.

Michela Craveri. Italiana. Doctora en Estudios Mesoamericanos por la Universidad Nacional Autónoma de México. Se desempeña como catedrática de Literatura Hispanoamericana en la Universidad Católica de Milán, Italia, y se ha especializado en el estudio de la retórica de la tradición oral maya (especialmente en el Popol Vuh), la cultura indígena colonial y el contacto con la población afrodescendiente. Su proyecto actual se titula "Cuerpo y literatura: estudio narratológico, modelos relacionales y prácticas discursivas alrededor del cuerpo, la enfermedad, la curación en la cultura y las literaturas hispanoamericanas". Entre sus publicaciones más recientes se encuentran "El señor del monte en la tradición oral maya. La narración mítica como normativa del orden del mundo: hombre, lluvia, viento, tierra y animales", "Aguas, raíces y tierra en el universo poético maya q'anjob'al: la poesía de Sabino Esteban Francisco" y "La poesía móvil y plural de Belice: Amado Chan y el cruce de fronteras".

michela.craveri@gmail.com 